\title{
An Overview of the Role of Mechanical Stretching in the Progression of Lung Cancer
}

\author{
Fengying Gong ${ }^{1}$, Yuchao Yang ${ }^{2}$, Liangtao Wen ${ }^{3}$, Congrong Wang ${ }^{4}$, Jingjun $\mathrm{Li}^{1 *}$ and \\ Jingxing Dai ${ }^{2 *}$
}

${ }^{1}$ Department of Traditional Chinese Medicine, Nanfang Hospital of Southern Medical University, Guangzhou, China, ${ }^{2}$ Guangdong Provincial Key Laboratory of Medical Biomechanics and Guangdong Engineering Research Center for Translation of Medical 3D Printing Application and National Key Discipline of Human Anatomy, School of Basic Medical Sciences, Southern Medical University, Guangzhou, China, ${ }^{3}$ Shiyue City Community Health Service Center, Shenzhen Integrated Traditional Chinese and Western Medicine Hospital, Shenzhen, China, ${ }^{4}$ Department of Laboratory Medicine, Nanfang Hospital of Southern Medical University, Guangzhou, China

\section{OPEN ACCESS}

Edited by: Daniele Vergara,

University of Salento, Italy

Reviewed by:

Andreas Stylianou,

European University Cyprus, Cyprus

Pranshu Sahgal,

Dana-Farber Cancer Institute,

United States

*Correspondence:

Jingjun $L i$

lijingjun@smu.edu.cn

Jingxing Dai

daijx@smu.edu.cn

Specialty section:

This article was submitted to Molecular and Cellular Oncology,

a section of the journal

Frontiers in Cell and Developmental

Biology

Received: 23 September 2021

Accepted: 09 December 2021

Published: 24 December 2021

Citation:

Gong $F$, Yang $Y$, Wen L, Wang $C$, Li J and Dai J (2021) An Overview of the Role of Mechanical Stretching in the

Progression of Lung Cancer.

Front. Cell Dev. Biol. 9:781828.

doi: $10.3389 /$ fcell.2021.781828
Cells and tissues in the human body are subjected to mechanical forces of varying degrees, such as tension or pressure. During tumorigenesis, physical factors, especially mechanical factors, are involved in tumor development. As lung tissue is influenced by movements associated with breathing, it is constantly subjected to cyclical stretching and retraction; therefore, lung cancer cells and lung cancer-associated fibroblasts (CAFs) are constantly exposed to mechanical load. Thus, to better explore the mechanisms involved in lung cancer progression, it is necessary to consider factors involved in cell mechanics, which may provide a more comprehensive analysis of tumorigenesis. The purpose of this review is: 1) to provide an overview of the anatomy and tissue characteristics of the lung and the presence of mechanical stimulation; 2) to summarize the role of mechanical stretching in the progression of lung cancer; and 3) to describe the relationship between mechanical stretching and the lung cancer microenvironment, especially CAFs.

\footnotetext{
Keywords: mechanical stretching, mechanotransduction, lung cancer, cancer-associated fibroblasts (CAFs), cancer microenvironment
}

\section{INTRODUCTION}

The main function of the lungs is to exchange oxygen and carbon dioxide with the outside world. The lung and thorax are important organs in the human respiratory system (Figure 1) (Novak et al., 2021). The respiratory muscles contract rhythmically, causing the thoracic volume to change periodically and then causing changes in pulmonary pressure, driving oxygen and carbon dioxide in and out of the lung to achieve pulmonary ventilation (Hsia et al., 2016; Doryab et al., 2021; Novak et al., 2021). Therefore, mechanical transduction plays a crucial role in lung health and disease. There are many types of mesenchymal cells in lung tissues. The fibroblast is one of the most important mesenchymal cells to maintain the normal physiological function of the lung. The

Abbreviations: CAFs, Cancer-associated fibroblasts; ECM, extracellular matrix; FEV1/FVC, forced expiratory volume to full forced lung capacity in one second; TLC\%, total lung capacity percentage; FEV1, forced expiratory volume in one second; PF, pulmonary fibrosis; $\alpha$-SMA, osteopontin, alpha smooth muscle actin; TGF- $\beta$, transforming growth factor- $\beta$. 


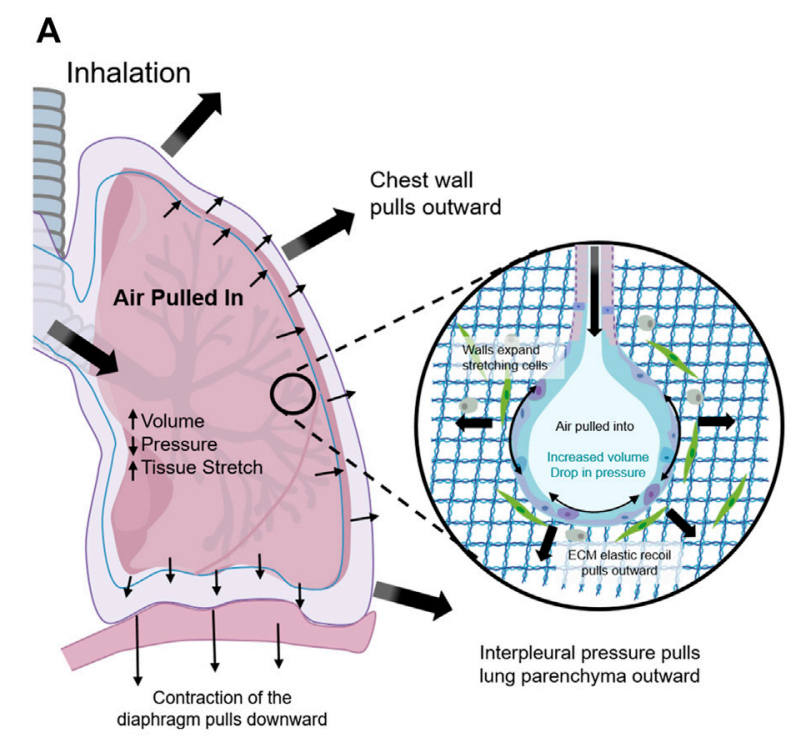

\section{B}
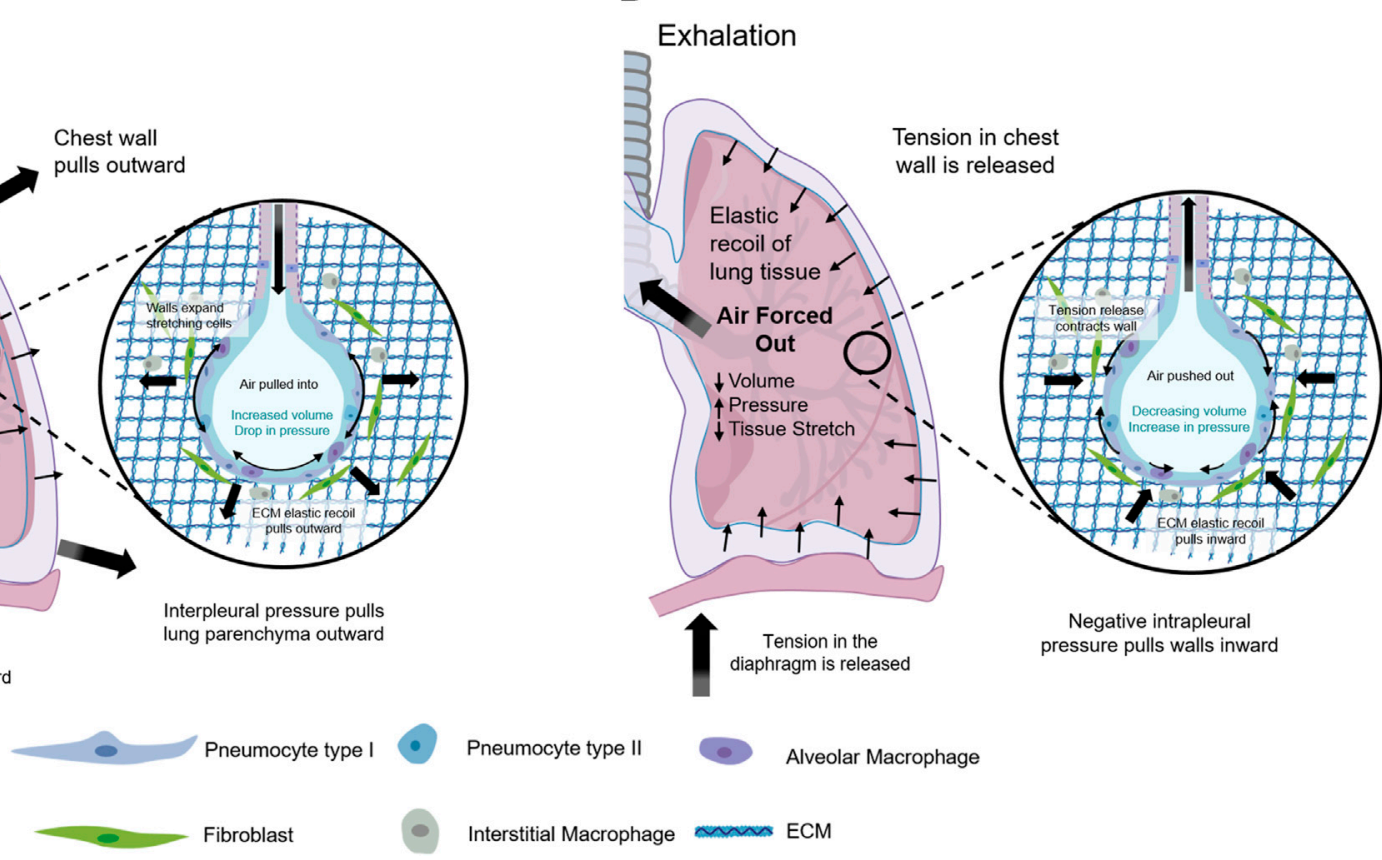

Pneumocyte type II

Alveolar Macrophage

Interstitial Macrophage m N ECM

FIGURE 1 | Mechanical Forces within the lung. (A) Contraction of the diaphragm and muscles in chest wall during inhalation led to negative interpleural pressure that enlarged lung tissue, stretched the alveoli, and increased lung volume driving air pulled in. (B) Relaxation of the diaphragm and muscles in chest wall during expiration permitted for elastic retreat that decreased lung volume and air compression that drove air forced out.

heterogeneity of fibroblasts is responsible for their different phenotypes and activities (Kotaru et al., 2006).

Lung tissue is constantly influenced by breathing mechanics, and it is constantly exposed to a state of cyclical stretching and retraction. Therefore, lung cancer cells and lung cancerassociated fibroblasts (CAFs) are also influenced by mechanical load (Najrana et al., 2020; Roshanzadeh et al., 2020). Fibroblasts are the cells that make and sustain a structurally diverse array of ECM-rich connective tissues to support a wide-ranging of vital organ functions, like resistance to blunt and sharp damages in the skin or organ-wide stretching and flexible recoiling in the undamaged breathing lung. Three functions are generally assigned to fibroblasts: 1) secrete many of the same structural and signaling macromolecules that donate to the extracellular space; 2) adopt a transient and contractile myofibroblast phenotype in response to tissue injury; 3) play an important role in signaling extracellular cells for tissueresident stem cells, or serve as mesenchymal stem cells, which can differentiate to specialized mesenchymal cells (Lemos and Duffield, 2018; Pittenger et al., 2019; Plikus et al., 2021). A main constituent of the tumor stroma is fibroblasts, and numerous studies have demonstrated a prominent functional role for these cells in cancer progression and metastasis (Kalluri and Zeisberg, 2006; Öhlund et al., 2014). Tumor related fibroblasts have been labeled CAFs, tumor associated fibroblasts, activated fibroblasts or activated myofibroblasts and could take in cancer-associated mesenchymal stem cells. To facilitate tissue repair, chemical and physical clues induce quiescent fibroblasts to myofibroblasts that secrete a lot of expressing contractile proteins in ECM such as a-SMA that coordinate biomechanical remodeling and contraction by traction (Plikus et al., 2017; Plikus et al., 2021).

Thus, to better explore the progression of lung cancer pathogenesis, it is necessary to combine cell mechanics factors to obtain a more comprehensive analysis. The purpose of this brief review is: 1) to provide an overview of the anatomy and tissue characteristics of the lung and the presence of mechanical stimulation; 2) to summarize the role of mechanical stretching in the progression of lung cancer; and 3) to describe the relationship between mechanical stretching and lung cancer microenvironment, especially CAFs.

\section{PHYSIOLOGICAL AND BIOMECHANICAL CHARACTERISTICS OF THE LUNG}

The lungs are in the chest cavity, on either side of the mediastinum, above the diaphragm. The lungs are composed of two functional areas: 1) the airways through which air enters and passes the pharynx, larynx, trachea, main bronchi, bronchioles, and terminal bronchioles; and 2) the respiratory zone (gas exchange zone), including the alveolar tubes, bronchioles, and alveolar sacs (Ahadian et al., 2018).

The main function of the lungs is to exchange gas with the outside world. Through the external respiration function of the lungs, oxygen $\left(\mathrm{O}_{2}\right)$ is continuously provided to the body and carbon dioxide $\left(\mathrm{CO}_{2}\right)$ is discharged to maintain the body's blood 
and gas balance and internal environment in equilibrium. The alveoli, which provide a large surface area for gas exchange, are lined with a thin layer of epithelial cells that form a tight single membrane on the basement membrane $(1.66 \pm 0.128 \mu \mathrm{m})$ in normal lungs (Divertie et al., 1976) and are directly connected to the endothelial lining of the capillary network. The space between the epithelium and endothelial lining is called the lung interstitium and contains various cellular and extracellular matrix (ECM) components that provide structure and support for the lungs (Novak et al., 2021).

\section{PATHOLOGICAL CHANGES OF LUNG}

In general, lung diseases fall into two categories: 1) restrictive diseases, which include a reduction in the ability of the lungs to expand and 2) obstructive diseases, which cause increased airway resistance and restricted airflow. Restrictive or obstructive diseases a classified based on clinical measures, including the ratio of forced expiratory volume to full forced lung capacity in one second (FEV1/FVC) and total lung capacity percentage (TLC $\%)$ (Kouranos et al., 2020). The restrictive disease is characterized by a decrease in the TLC\% with no change or increase in the FEV1/FVC ratio because either both indicators decrease simultaneously or forced expiratory volume in one second (FEV1) increases with decreased lung compliance. Restrictive diseases, such as pulmonary fibrosis, interstitial lung disease, and sarcoidosis, often result from the accumulation of components of the ECM and scar tissue around the alveoli that affects the stiffness of the lung parenchyma and limits the lung's ability to expand. Obstructive diseases, such as asthma, bronchopulmonary dysplasia, bronchiolitis obliteration, and chronic obstructive pulmonary disease, due to the degradation of lung connective tissue, lead to airway swelling, reduced matrix hardness and elasticity, and reduced lung retraction, and interfere with an individual's ability to exhale adequately (Novak et al., 2021).

Pulmonary fibrosis (PF) is a chronic, restrictive lung disease in which excessive collagen deposition results from the accumulation of scar tissue in the lung caused by lung injury, inflammation, and/or long-term exposure to toxins or particles. Idiopathic pulmonary fibrosis (IPF) is a chronic progressive pulmonary fibrosis disease with unknown reasons. In recent years, more and more studies have shown that IPF is closely related to the occurrence of lung cancer. Also, IPF diagnosis and treatment guidelines in 2011 clearly indicate that IPF is prone to lung cancer, pulmonary embolism, pulmonary hypertension, and other lung diseases (Raghu et al., 2011; Raghu et al., 2015). According to the latest research statistics, the incidence of lung cancer in IPF population is $2.7-48 \%$ (Ballester et al., 2019), which is significantly higher than that of the general population (2-6.4\%) (Bouros et al., 2002). Undissolved scar tissue in the lungs hardens the lung parenchyma and limits lung dilation. Matrix over deposition occurs in the distal airway structure, where fibroblast lesions are composed of excess collagen, fibrin, and other ECM components that are insoluble and deteriorate over time (Burgess et al., 2016).
Heterogeneous lung stiffness results in increased stress and strain, affecting cellular mechanical conduction and disease progression. Tsukui et al. (2013) constructed an in vivo model of bleomycin-induced pulmonary fibrosis to study the gene expression profile of fibroblast populations. They found that osteopontin is highly overexpressed in lung fibroblasts and can serve as a marker of CAFs activation. It has been reported that biomarkers commonly expressed by CAFs include a -smooth muscle actin (a-SMA), fibroblast specific protein-1 (FSP-1), fibroblast activating protein $\alpha(\mathrm{FAP}-\alpha)$, platelet-derived growth factor receptor $-\beta$ (PDGFR- $\beta$ ), neural/glial antigen (NG2) (Kalluri, 2016; Nurmik et al., 2019), and Gammaglutamyltransferase 5 (GGT5) (Wei et al., 2020). Su S et al. reported $\mathrm{CD} 10^{+} / \mathrm{GPR} 77^{+} \mathrm{CAF}$ promoted cancer development and chemoresistance by sustaining cancer stemness ( $\mathrm{Su}$ et al., 2018). Interestingly, osteopontin expression is significantly increased in senescent fibroblasts and is a key mediator of senescent stroma promoting tumor progression (Pazolli et al., 2009).

\section{ASSOCIATION BETWEEN MECHANICAL STRETCHING OF THE LUNG AND LUNG CANCER}

Cells respond to both chemical and mechanical signals in their microenvironment. Various mechanical stimulus signals (e.g., basal rigidity, hydrostatic pressure, compression, tension, and shear stress) are detected and transmitted to cells via mechanoreceptors. These receptors often encounter the ECM, where external signals are converted into physiological responses that affect cell proliferation, differentiation, and migration (Jang and Beningo, 2019).

\section{Studies on Cell Mechanics Involving Lung Tissue Cells}

A major feature of the lung is its unique mechanical force. Each respiratory cycle imposes a periodic mechanical force, and this dynamic mechanical force exposes the lung to a challenging system of external reconstruction (Ahadian et al., 2018). The experiments by Tschumperlin and Margulies have shown that circulatory stretching stimulation of $5-12 \%$ is equivalent to $60-80 \%$ of the total lung volume and is associated with the physiological level of mechanical strain experienced by the alveolar epithelium and microvessels during low tidal volume mechanical ventilation, which is the protocol used in lung protection strategies (Tschumperlin and Margulies, 1998; Tschumperlin and Margulies, 1999). In contrast, circulatory stretching at $17-22 \%$ linear dilation is equivalent to $100 \%$ of total lung volume and is associated with pathophysiological conditions induced by mechanical ventilation of the organism volume and with inflammatory responses in vivo and with acute lung injury (Tschumperlin et al., 2000).

The lung is a dynamic organ with complex mechanical environment at microscale (Shikata et al., 2005). Thus, mechanotransduction plays a vital role in lung health and 
TABLE 1 | Stimulation experiments of lung cancer cells by mechanical stretching.

\begin{tabular}{|c|c|c|c|}
\hline Cell type & Mechanical stretching & Results & References \\
\hline $\begin{array}{l}\text { Lung epithelial cancer } \\
\text { cells (A549) } \\
\text { Fibroblast (IMR-90) }\end{array}$ & $\begin{array}{l}\text { Short-term stretching }(15,30 \text {, and } 60 \mathrm{~min}) \text { and long-term } \\
\text { stretching }(24 \mathrm{~h}), 10 \% \text { cell surface area, } 1 \mathrm{~Hz} \text {, incubated } \\
\text { at } 37^{\circ} \mathrm{C}\end{array}$ & $\begin{array}{l}\text { Cell rearrangement, cytoskeleton reorganization, and } \\
\text { increased stretching time can prolong mitochondrial length }\end{array}$ & $\begin{array}{l}\text { Wang et al. } \\
(2020)\end{array}$ \\
\hline $\begin{array}{l}\text { AT II cell-like A549 } \\
\text { serous glandular } \\
\text { epithelial cell-like Calu-3 } \\
\mathrm{NCl}-\mathrm{H} 322 \\
\mathrm{NCl}-\mathrm{H} 358 \\
\text { Lung epithelial cancer } \\
\text { cells (BEAS-2B) }\end{array}$ & $16 \%$ surface elongation, $12 \mathrm{~min}^{-1}$ & $\begin{array}{l}\text { Several kinds of human lung epithelial cell lines can adapt to } \\
\text { chronic cyclic strain }\end{array}$ & $\begin{array}{l}\text { Wang et al. } \\
\text { (2020) }\end{array}$ \\
\hline $\begin{array}{l}\text { Lung epithelial cancer } \\
\text { cells (A549) } \\
\mathrm{NCl}-\mathrm{H} 358\end{array}$ & $20 \%$ maximum strain and 15 cycles/minute & Decrease cell proliferation & $\begin{array}{l}\text { Hendricks et al. } \\
\text { (2012) }\end{array}$ \\
\hline
\end{tabular}

disease. The effects of mechanical force on proliferation, morphology, ECM composition, and alteration, gene regulation and the inflammatory response of lung cells and lung cancer cells have been recognized by most researchers (Novak et al., 2021). Nalayanda et al. (2009) observed that the growth rate of A549 cells decreased as the shear stress increased. However, Mahto et al. demonstrated that the effect of shear stress on alveolar cells was affected by cell species. The secretion of surface-active substances in human A549 cells showed no change below 8 dynes $/ \mathrm{cm}^{2}$, but was impaired when it was above 8 dynes/ $\mathrm{cm}^{2}$. The secretion of mouse MLE-12 cells increased with the growth of stimulation (Mahto et al., 2014). There are conflicting findings in the literature on the role of matrix rigidity on epithelial cell function. Eisenberg et al. (Jones, 2011) established that substrate rigidity affected cell morphology, microfilaments, and focal adhesion, but did not adjust the differentiation of EMT or cell types (from ATII into ATI) in mouse alveolar epithelial cells. In contrast, Marilyn M. Dysart et al. found that environmental particulate enhances stiffness induced alveolar epithelial cells mechanoactivation of TGF- $\beta$ (Dysart et al., 2014). Markowski et al. (2012), reported that augmented matrix rigidity induced EMT, integrin binding, and TGF- $\beta$ activation. The cell mechanics of lung cancer cells will discuss in the next section.

Many researchers have developed in vitro systems to detect the response of lung cells to mechanical forces. These models typically study how one type of mechanical force affects one cell type, and there is very little work combining multidimensional forces and multicellular models to accurately summarize the complex interactions that occur in the body. Typical devices in vitro mechanical stimulation involved: 1) cyclic uniaxial or biaxial, equi-biaxial strain for cell stretch stimulation (Felder et al., 2008; Rapalo et al., 2015) 2) static or cyclic pressure devices on cell stimulation (Huang et al., 2010); 3) microfluidic device for wall shear stress on cells (Mahto et al., 2014); 4) gradient stiffness hydrogel for cell culture (Liu et al., 2010); 5) cyclic strain device for capillary interface (Huh et al., 2010); 6) interstitial fluid flow custom device for cells seeded on the gel (Ng and Swartz, 2003). The effects of endothelial cells stimulated by shear stress have been widely studied. Shear stress is a known factor impacting endothelial cell morphology (Szulcek et al., 2016), cytoskeletal remodeling (Birukov et al., 2002), and
$\mathrm{Ca}^{2+}$ levels in plasma (Yamamoto et al., 2018). Nitric oxide release is donated to maintain vasomotor action, anti-inflammatory mechanism, and cytoplasmic antioxidant ability (Tousoulis et al., 2012). Endothelial cells increased their ACE2 expression with pulsating shear stress stimulated, thereby enhancing the level of nitric oxide and decreasing proliferation and inflammation. ACE2 level was enlarged when endothelial cells were stimulated and stretched in the Flexcell device (Song et al., 2020).

\section{Studies on Cell Mechanics on Lung Cancer Cells}

Like normal cells, cancer cells recognize the mechanical changes provided by the tumor microenvironment and convert them into signaling pathways through mechanical transduction pathways (Table 1) (Sporn and Albini, 2007; Xu et al., 2017). Wang et al. (2020) found that after cyclic stretching of the A549 lung cancer and IMR-90 fibroblast cells, cells were rearranged, the cytoskeleton was restructured, and an increased stretching time could prolong mitochondrial length. Weber et al. (Wang et al., 2020) found that various human lung epithelial cell lines could adapt to chronic cyclic strain stimulation. Hendricks et al. (2012) studied the effects of the simulated force of near-normal respiration $(20 \%$ maximum strain and 15 cycles/min) on proliferation and morphology of NCI-H358 and A549 cell lines. They showed that mechanical stimulation reduced cell proliferation. Shukla et al. (2016) demonstrated that higher substrate rigidity induced slower and directional migration of lung cancer cells by decreasing the phosphorylated focal adhesion kinase and paxillin, not the biomarkers of EMT. Furthermore, Barenholz Cohen et al. (2020) demonstrated that tumor-derived extracellular vesicles from breast carcinoma cells caused the lungs of cancer-free mice broadly variable, and being more elastic than viscous. Matrix rigidity encourages microtubules glutamylation by increasing glutamine metabolism and strengthening microtubules stabilization, thus stimulating the migration of cancer cells (Torrino et al., 2021).

\section{CAFs and Studies on Cell Mechanics} Fibroblasts and Mechanical Stimulation

The lung is a complex organ, and types of mesenchymal cells are found in its tissues. Fibroblasts are one of the most important 
TABLE 2 | Stimulation experiments of lung fibroblasts by mechanical stretching.

\begin{tabular}{|c|c|c|c|}
\hline Cell type & Mechanical stretching & Results & References \\
\hline $\begin{array}{l}\text { Human embryonic lung } \\
\text { fibroblast MRC-5 }\end{array}$ & $\begin{array}{l}\text { Flexcell FX-5000; mechanical tensile stimulation } \\
\text { continuously for } 48 \mathrm{~h}(0.1 \mathrm{~Hz} \text {; Sine waves, stretching } \\
\text { amplitude of } 5,10,15 \text { and } 20 \%)\end{array}$ & $\begin{array}{l}\text { Mechanical stimulation of } 5 \% \text { stretching increased cell } \\
\text { proliferation. However, it had no significant effect on } \\
\text { expression levels of TGF- } \beta 1 \text { and collagen. Mechanical } \\
\text { stimulation with } 10 \% \text { tensile force inhibited cell } \\
\text { proliferation but increased expression levels of TGF- } \beta 1 \\
\text { and type I collagen. } 15 \text { and } 20 \% \text {, with significantly larger } \\
\text { effects }\end{array}$ & Xie et al. (2020) \\
\hline human lung fibroblasts & $\begin{array}{l}\text { Strex ST-140; uniaxial tension (strain 10-30\%); } 30 \\
\text { cycle/min for } 10 \text { min }\end{array}$ & $\begin{array}{l}\text { Mechanical stretching induces calcium influx and } \\
\text { releases ATP independently of conventional stretch- } \\
\text { sensitive ion channels, known as actin cytoskeleton }\end{array}$ & Murata et al. (2014) \\
\hline human lung fibroblasts & $\begin{array}{l}\text { Flexercell FX-4000; } 0.2 \mathrm{HZ} \text {, maximum elongation } \\
10 \%, 24 \text { or } 48 \mathrm{~h} \text { of cyclic mechanical strain }\end{array}$ & $\begin{array}{l}\text { The mRNA expressions of COL1A1, COL1A2, } \\
\text { COL3A1, COL5A2 and Tenascin C were decreased. } \\
\text { Cyclic mechanical loading on primary human lung } \\
\text { fibroblasts for } 48 \text { h reduced the expression of fibrosis- } \\
\text { related genes. Myofibroblast differentiation is reduced } \\
\text { under these conditions. cyclic mechanical loading } \\
\text { decreased the expression of endogenous TGF- } \beta 1\end{array}$ & Blaauboer et al. (2011) \\
\hline \multirow[t]{2}{*}{$\begin{array}{l}\text { Mouse fetal lung fibroblasts: } \\
\text { wild-type and EGFR } \\
\text { knockout }\end{array}$} & $\begin{array}{l}\text { Flexcell FX-4000; equibiaxial cyclic strain of } 2.5 \% \text { or } \\
20 \% \text { was applied at } 40 \text { cycles per min intervals } \\
\text { for } 48 \mathrm{~h}\end{array}$ & $\begin{array}{l}\text { Traumatic stretch ( } 20 \% \text { stretch) results in lactate } \\
\text { dehydrogenase release at the same level in wild-type } \\
\text { and knockout cells. EGFR does not alter the mechanical } \\
\text { properties and damage resistance of fetal fibroblasts } \\
\text { exposed to mechanical stretching }\end{array}$ & Giordani et al. (2013) \\
\hline & $\begin{array}{l}\text { A } 2.5 \% \text { stretching scheme was selected to simulate } \\
\text { physiological stretching and } 20 \% \text { to simulate injury }\end{array}$ & $\begin{array}{l}20 \% \text { stretching increased lysed caspase- } 3 \text { and } \\
\text { decreased proliferating nuclear antigen only in wild-type } \\
\text { cells. } 20 \% \text { stretching increased macrophage } \\
\text { inflammatory protein- } 2 \text { and monocyte chemotactic } \\
\text { protein- } 1 \text { in wild-type cells. In knockout cells, miP-2 } \\
\text { was reduced by } 50 \% \text { and McP-1 increased by only } \\
60 \% \text { compared to physiological stretching }\end{array}$ & \\
\hline Mouse fetal lung fibroblasts & $\begin{array}{l}\text { Flexcell FX-4000 Strain Unit; } 20 \% \text { cyclic stretch, } 40 \\
\text { cycles/min for } 48 \text { h }\end{array}$ & $\begin{array}{l}\text { After } 24 \text { h, LDH levels had increased by } 50 \% \text {. After } 48 \text { h } \\
\text { mechanical stretching, fibroblast lysis increased }\end{array}$ & $\begin{array}{l}\text { Hawwa et al. (2011a), } \\
\text { Hawwa, et al. (2011b) }\end{array}$ \\
\hline
\end{tabular}

mesenchymal cells that contribute to maintaining the lung's normal physiological function. The heterogeneity of fibroblasts is the key reason for their different phenotypes and functions (Öhlund et al., 2014). Fibroblasts from different parts of the lung present significant differences and can be divided into different subgroups according to their heterogeneity (Chang et al., 2002; Kotaru et al., 2006). Kotaru et al. (2006) found that there are two kinds of fibroblasts at least: Airway fibroblasts (AFs) and distal lung fibroblasts (DLFs). AFs are larger, stellate-shaped with more cytoplasmic protrusions, and DLFs are spindle-shaped. AFs expressed more procollagen type I and eotaxin-1 than DLFs did at and after TGF- $\beta$ treatment. In contrast, AFs had low proliferation rate than DLFs with serum treatment. Moreover, AFs expressed less a-SMA than DLFs in reference point. Pechkovsky et al. (2010) demonstrated results by comparing human proximal bronchi (B-FBR) and distal lung parenchyma (P-FBR). It indicated that P-FBR showed improved TGF- $\beta /$ Smad signaling at the reference point, and the activated TGF- $\beta$ significantly reduced basal a-SMA protein in P-FBR. Xie et al. (2018) segregated six subpopulations in adult pulmonary mesenchymal cells: myofibroblasts, Col13al matrix fibroblasts, Col14a1 matrix fibroblasts, lipofibroblasts, mesenchymal progenitors, and mesothelial cells.

Fibroblasts are cells that respond to mechanical stretching stimuli (Table 2). They maintain the structure and function of organ tissues by altering the expression of genes and proteins in their ECM in response to external physical (such as tensile force), chemical (such as chemical poisons), and biological (such as infectious toxins) factors (Amma et al., 2005; Sakamoto et al., 2010).

Pechkovsky et al. (2010) found that fibroblasts derived from the lung parenchyma cilia develop $\alpha$-SMA, whose high expression characterizes a specific fibroblast phenotype. These cells are responsible for the composition of the ECM. Components, mainly cellular protein deposition, may be involved in the pathogenesis of idiopathic pulmonary fibrosis, and fiber proliferative disease and may play a key role in the occurrence and development of lung cancer. The cyclic load to which healthy lung cells are exposed during respiration prevents fibroblasts from differentiating into myofibroblasts (Blaauboer et al., 2011). suggesting that fibroblasts are static in their physiological state. Low levels of mechanical stretching may be important for interstitial remodeling during lung development. However, extensive stretching can damage the normal lung structure (Hawwa et al., 2011a; Sanchez-Esteban et al., 2002).

After the lung tissue is slightly injured, fibroblasts in the lung parenchyma differentiate into myofibroblasts (Tomasek et al., 2002) to promote wound healing. After tissue repair, apoptosis of myofibroblasts occurs once the remodeling balance of repaired tissue is restored. During fibrosis, however, myofibroblasts remain active after wound healing, producing an excess of strongly contracted ECM components. Xie et al. (2020) showed that (5-10\%) mechanical stimulation could improve the proliferative activity of MRC-5 cells and may slightly 


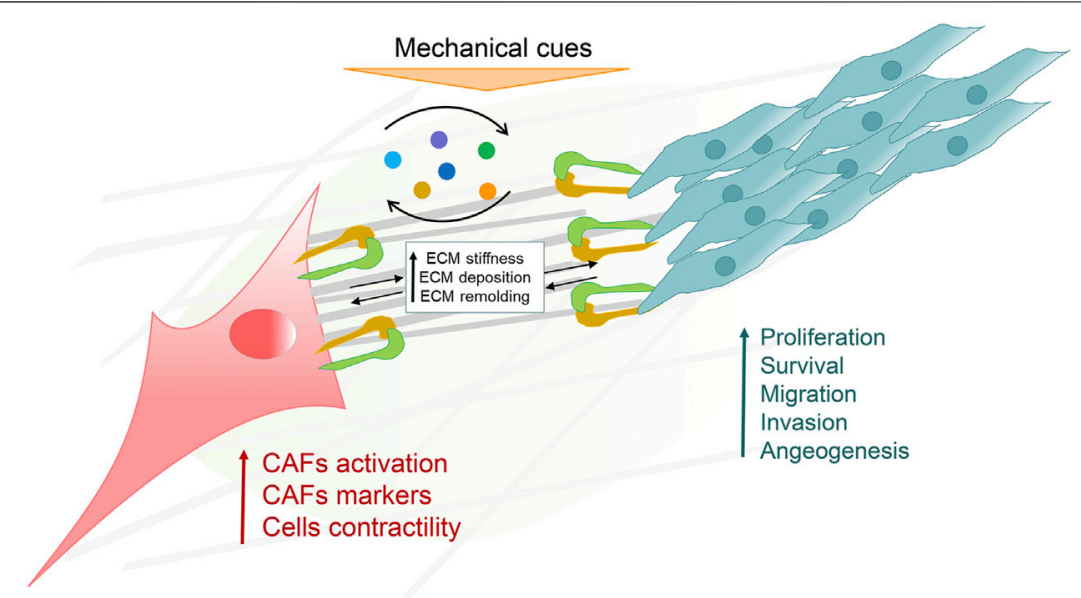

FIGURE 2 | The crosstalk of cancer associated fibroblasts (CAFs) and the cancer microenvironment (CME). CAFs and cancer cells are responsible for sensing and transducing various extracellular matrix (ECM) proteins and mechanical signals in the CME. CAFs and cancer cells also effect each other's physiological processes by releasing and receiving various factors in a paracrine manner.

stimulate the expression of transforming growth factor- $\beta$ (TGF$\beta) 1$ and type I collagen in human embryonic lung fibroblasts. Mechanical stimulation (15-20\%) directly leads to cell damage, reduces cell proliferation activity, induces TGF- $\beta 1$ expression, significantly increases collagen expression, and accelerates the process of pulmonary fibrosis.

After mechanical stimulation at different tensile ranges, the biomechanical properties of MRC-5 fibroblast cells decreased. And, the fibroblasts appeared to "soften", indicating that the degree of deformation of lung fibroblasts was lower than the linear stress-strain relationship. This feature is not a reflection of a specific molecular mechanism but indicates higher-level structural changes, which suggests that the cytoskeleton may have been damaged (Xie et al., 2020). Other in vitro studies have shown that mechanical stretching with higher strain ranges (20-30\%) activates the $\mathrm{Ca}^{2+}$ influx pathway independently of the actin cytoskeleton and the conventional stretch sensitive ion channel (such as members of the transient receptor potential (TRP) family proteins, Piezo1, and Piezo2). Moreover, ATP is released in human lung fibroblasts after mechanical stretching (Murata et al., 2014). It is also suggested that $\mathrm{Ca}^{2+}$ is the second messenger that activates lung fibroblast functional activity (Hinz, 2012). However, an increase in the extracellular ATP concentration is considered a "danger signal" in the pathophysiology of pulmonary fibrosis (Riteau et al., 2010). Therefore, increased $\mathrm{Ca}^{2+}$ in lung fibroblasts responding to mechanical stress plays a role in the progression of pulmonary fibrosis.

Fibroblasts release more pro-inflammatory cytokines and chemokines after mechanical stretching, which actively participate in regulating the inflammatory response after mechanical injury (Hawwa et al., 2011a) and promote wound healing and tissue repair. Lung fibroblasts play a key role in pathophysiological events associated with pulmonary fibrosis (Barkauskas and Noble, 2014; Riteau et al., 2010; Yamauchi et al., 2020).

\section{Cancer-Associated Fibroblasts Exposed to Stretching Stimulation}

Cancer is known as "wounds that never heal", and fibroblasts activated in the tumor ECM can promote tumor inflammation and fibrosis (Kalluri, 2016); thus, they are also known as CAFs. Compared with resting fibroblasts, CAFs present a larger morphology, nuclear depression, and more branching cytoplasm (De Wever et al., 2008), and activated CAFs have stronger proliferation and migration ability (Chen and Song, 2019).

CAFs are cells with mechanical ability and are the most abundant stromal cell type in the tumor microenvironment (Bhowmick et al., 2004). They play a crucial role in cancer development and metastasis (Pereira et al., 2019). Once CAFs settle down in ECM of the tumor, they can benefit cancer cells in many aspects: 1) promote the growth and proliferation of tumor cells (Zhang et al., 2020); 2) assist in tumor-related angiogenesis (Fan et al., 2020; Lugano et al., 2020); 3) accelerate the invasion and metastasis of tumor cells (Birkbak and McGranahan, 2020); 4) cause drug resistance of some anti-tumor drugs (Wei et al., 2020). CAFs secrete soluble factors such as growth factors, cytokines, and ECM molecules during cancer progression to promote the self-differentiation of normal fibroblasts. TGF- $\beta$ released by CAFs triggers the anisotropic matrix to stimulate myofibroblast differentiation of normal fibroblasts (FrancoBarraza et al., 2017). Meanwhile, excessive production of fibrillary ECM proteins and ECM remodeling by CAFs leads to cancer fibrosis, namely promoting connective tissue hyperplasia. As the stiffness of the ECM derived from CAFs increases, it usually leads to greater force (traction) exerted by cells on the matrix, as well as increased stress fibers and greater focal adhesion (Ladoux et al., 2016), thus promoting the differentiation of CAFs and supporting the progression of cancer.

There is an inverse relationship between traction stress and metastatic capacity of breast cancer cells, and the generation of force decreases with the increase of metastatic potential and capacity (Indra et al., 2011). Studies have shown that cell- 
matrix adhesion dynamics and traction conversion regulate tumor cell migration (Fokkelman et al., 2016). Recent studies have shown that CAFs exert physical forces on cancer cells by stimulating phenotypically pro- or anti-tumorigenic interactions that allow them to invade en masse (Yamauchi et al., 2020).

Glentis et al. (2017) found that CAFs actively reshape the basement membrane by pulling, stretching, and softening it, leading to the formation of spaces where cancer cells can migrate. By applying contractile forces, CAFs alter the organizational and physical properties of the basement membrane, allowing cancer cells to invade. CAFs promote fracture of the bone matrix in a matrix metalloproteinaseindependent manner. Therefore, it has been proposed that in addition to proteolysis, the mechanical forces exerted by CAFs represent another mechanism of basement membrane rupture.

In the tumor microenvironment, CAFs and cancer cells communicate through the ECM and other soluble factors to influence each other's cellular behavior (Figure 2). Numerous mechanical signals are detected and transmitted to cells by mechanoreceptors. These receptors often communicate with ECM, where external signals are converted into physiological replies. Integrin was a well-defined mechanoreceptor that directly connected the microfilaments to the ECM and conducted signals. The $18 \alpha$ and $8 \beta$ subunits heterodimerize to produce more than 24 different receptors. These heterodimers are the link between cells and the tumor microenvironment. CAFs heterogeneity drives balancing processes in tumor growth and invasion (DiPersio and Van De Water, 2019; Jang and Beningo, 2019). Tumor growing accompanied with a heterogeneous population of CAFs. The subpopulations of CAFs can promote deposition and ECM remodeling, which interact directly with tumor cells in principal and subordinate structures to help tumor cell migration and invasion. Also, it provokes angiogenic factors by mediating new blood vessel growth and yield immune cell suppression via ECM modification and chemokine/cytokine secretion (Yamauchi et al., 2020). Although this communication is bi-directional, as shown in the figure, we mainly consider communication as unidirectional, from CAFs to cancer cells. Mechanical forces generated by ECM remodeling induced by CAFs contribute to the invasion efficiency of metastatic cells (Menon et al., 2011).

\section{CONCLUDING REMARKS AND OUTSTANDING QUESTIONS}

Mechanical stimulation is closely related to lung, lung cancer, and lung cancer-related fibroblasts. Mechanical strain is an important

\section{REFERENCES}

Ahadian, S., Civitarese, R., Bannerman, D., Mohammadi, M. H., Lu, R., Wang, E., et al. (2018). Organ-On-A-Chip Platforms: A Convergence of Advanced Materials, Cells, and Microscale Technologies. Adv. Healthc. Mater. 7 (2), 1700506. doi:10.1002/adhm.201700506

Albini, A., and Sporn, M. B. (2007). The Tumour Microenvironment as a Target for Chemoprevention. Nat. Rev. Cancer 7 (2), 139-147. doi:10.1038/nrc2067 regulator of normal and abnormal lung growth and development. Mechanical forces are involved in biological processes ubiquitously (Kumar and Weaver, 2009), although the underlying mechanisms of cancer cell migration or metastasis are still not fully understood. Mechanical stimulation plays an important role in regulating fibroblasts and the ECM components within the tumor microenvironment. First, there is no literature available on the mechanisms induced in lung CAFs by mechanical stimulation. Secondly, a limited number of studies have described mechanisms induced by mechanical stimulation of other types of CAFs. However, these studies suggested that CAFs play a crucial role in tumor progression. Thirdly, the response of lung CAFs to mechanical stimulation may play a crucial role in the progression of lung cancer; thus, it will be of great clinical significance to study the response of lung CAFs to mechanical stimulation.

At present, lung biomechanics are mainly focused on mechanical ventilation, ventilation injury and fluid dynamics of vascular endothelial cells. There is a lack of research on mechanical factors affecting other lung cells (especially fibroblasts and immune cells) in normal respiration. There are few studies on the mechanism of lung tumors causing changes in lung physical properties and then affecting lung cells.

Due to the complexity of the lung cancer classification, there may be different types of lung CAFs, but once this role of mechanotransduction on lung cancer cells is recognized, this will be accompanied by further in-depth research. In the future, it will be extremely challenging and of practical significance to isolate different types of lung CAFs associated with different types of lung cancer, and elucidate the specific mechanisms involved in mechanical stimulation on tumor progression.

\section{AUTHOR CONTRIBUTIONS}

FG, JL, and JD organization of content and structure, writing and reviewing; YY preparation of figures, writing and reviewing; LW and CW writing and reviewing. All authors agree to be accountable for the content of the work.

\section{FUNDING}

This study was supported by Scientific research project of Traditional Chinese Medicine Bureau of Guangdong Province (20201232) and the President's Fund of Nanfang Hospital (2019C033).

Amma, H., Naruse, K., Ishiguro, N., and Sokabe, M. (2005). Involvement of Reactive Oxygen Species in Cyclic Stretch-Induced NF-Kb Activation in Human Fibroblast Cells. Br. J. Pharmacol. 145 (3), 364-373. doi:10.1038/ sj.bjp.0706182

Ballester, B., Milara, J., and Cortijo, J. (2019). Idiopathic Pulmonary Fibrosis and Lung Cancer: Mechanisms and Molecular Targets. Ijms 20 (3), 593. doi:10.3390/ijms20030593

Barenholz-Cohen, T., Merkher, Y., Haj, J., Shechter, D., Kirchmeier, D., Shaked, Y., et al. (2020). Lung Mechanics Modifications Facilitating Metastasis Are 
Mediated in Part by Breast Cancer-derived Extracellular Vesicles. Int. J. Cancer 147 (10), 2924-2933. doi:10.1002/ijc.33229

Barkauskas, C. E., and Noble, P. W. (2014). Cellular Mechanisms of Tissue Fibrosis. 7. New Insights into the Cellular Mechanisms of Pulmonary Fibrosis. Am. J. Physiology-Cell Physiol. 306 (11), C987-C996. doi:10.1152/ajpcell.00321.2013

Bhowmick, N. A., Neilson, E. G., and Moses, H. L. (2004). Stromal Fibroblasts in Cancer Initiation and Progression. Nature 432 (7015), 332-337. doi:10.1038/ nature03096

Birkbak, N. J., and McGranahan, N. (2020). Cancer Genome Evolutionary Trajectories in Metastasis. Cancer Cell 37 (1), 8-19. doi:10.1016/ j.ccell.2019.12.004

Birukov, K. G., Birukova, A. A., Dudek, S. M., Verin, A. D., Crow, M. T., Zhan, X., et al. (2002). Shear Stress-Mediated Cytoskeletal Remodeling and Cortactin Translocation in Pulmonary Endothelial Cells. Am. J. Respir. Cel Mol Biol 26 (4), 453-464. doi:10.1165/ajrcmb.26.4.4725

Blaauboer, M. E., Smit, T. H., Hanemaaijer, R., Stoop, R., and Everts, V. (2011). Cyclic Mechanical Stretch Reduces Myofibroblast Differentiation of Primary Lung Fibroblasts. Biochem. Biophysical Res. Commun. 404 (1), 23-27. doi:10.1016/j.bbrc.2010.11.033

Bouros, D., Hatzakis, K., Labrakis, H., and Zeibecoglou, K. (2002). Association of Malignancy with Diseases Causing Interstitial Pulmonary Changes. Chest 121 (4), 1278-1289. doi:10.1378/chest.121.4.1278

Burgess, J. K., Mauad, T., Tjin, G., Karlsson, J. C., and Westergren-Thorsson, G. (2016). The Extracellular Matrix - the Under-recognized Element in Lung Disease? J. Pathol. 240 (4), 397-409. doi:10.1002/path.4808

Chang, H. Y., Chi, J.-T., Dudoit, S., Bondre, C., van de Rijn, M., Botstein, D., et al. (2002). Diversity, Topographic Differentiation, and Positional Memory in Human Fibroblasts. Proc. Natl. Acad. Sci. 99 (20), 12877-12882. doi:10.1073/pnas.162488599

Chen, X., and Song, E. (2019). Turning Foes to Friends: Targeting CancerAssociated Fibroblasts. Nat. Rev. Drug Discov. 18 (2), 99-115. doi:10.1038/ s41573-018-0004-1

De Wever, O., Demetter, P., Mareel, M., and Bracke, M. (2008). Stromal Myofibroblasts Are Drivers of Invasive Cancer Growth. Int. J. Cancer 123 (10), 2229-2238. doi:10.1002/ijc.23925

DiPersio, C. M., and Van De Water, L. (2019). Integrin Regulation of CAF Differentiation and Function. Cancers 11 (5), 715. doi:10.3390/ cancers 11050715

Divertie, M. B., Cassan, S. M., and Brown, A. L. (1976). Ultrastructural Morphometry of the Blood-Air Barrier in Pulmonary Sarcoidosis. Chest 69 (2), 154-157. doi:10.1378/chest.69.2.154

Doryab, A., Taskin, M. B., Stahlhut, P., Schröppel, A., Orak, S., Voss, C., et al. (2021). A Bioinspired In Vitro Lung Model to Study Particokinetics of Nano-/ Microparticles under Cyclic Stretch and Air-Liquid Interface Conditions. Front. Bioeng. Biotechnol. 9, 616830. doi:10.3389/fbioe.2021.616830

Dysart, M. M., Galvis, B. R., Russell, A. G., and Barker, T. H. (2014). Environmental Particulate (PM2.5) Augments Stiffness-Induced Alveolar Epithelial Cell Mechanoactivation of Transforming Growth Factor Beta. PLoS One 9 (9), e106821. doi:10.1371/journal.pone.0106821

Fan, J., Xu, G., Chang, Z., Zhu, L., and Yao, J. (2020). MiR-210 Transferred by Lung Cancer Cell-Derived Exosomes May Act as Proangiogenic Factor in CancerAssociated Fibroblasts by Modulating JAK2/STAT3 Pathway. Clin. Sci. 134 (7), 807-825. doi:10.1042/CS20200039

Felder, E., Siebenbrunner, M., Busch, T., Fois, G., Miklavc, P., Walther, P., et al. (2008). Mechanical Strain of Alveolar Type II Cells in Culture: Changes in the Transcellular Cytokeratin Network and Adaptations. Am. J. Physiology-Lung Cell Mol. Physiol. 295 (5), L849-L857. doi:10.1152/ajplung.00503.2007

Fokkelman, M., Balcığlu, H. E., Klip, J. E., Yan, K., Verbeek, F. J., Danen, E. H. J., et al. (2016). Cellular Adhesome Screen Identifies Critical Modulators of Focal Adhesion Dynamics, Cellular Traction Forces and Cell Migration Behaviour. Sci. Rep. 6 (1), 31707. doi:10.1038/srep31707

Franco-Barraza, J., Francescone, R., Luong, T., Shah, N., Madhani, R., Cukierman, G., et al. (2017). Matrix-regulated Integrin $\alpha v \beta 5$ Maintains $\alpha 5 \beta 1$-dependent Desmoplastic Traits Prognostic of Neoplastic Recurrence. eLife 6, e20600. doi:10.7554/eLife. 20600

Giordani, V. M., DeBenedictus, C. M., Wang, Y., and Sanchez-Esteban, J. (2013). Epidermal Growth Factor Receptor (EGFR) Contributes to Fetal Lung
Fibroblast Injury Induced by Mechanical Stretch. J. Receptors Signal Transduction 34 (1), 58-63. doi:10.3109/10799893.2013.862270

Glentis, A., Oertle, P., Mariani, P., Chikina, A., El Marjou, F., Attieh, Y., et al. (2017). Cancer-associated Fibroblasts Induce Metalloprotease-independent Cancer Cell Invasion of the Basement Membrane. Nat. Commun. 8 (1), 924. doi:10.1038/s41467-017-00985-8

Hawwa, R. L., Hokenson, M. A., Wang, Y., Huang, Z., Sharma, S., and SanchezEsteban, J. (2011b). Differential Expression of MMP-2 and -9 and Their Inhibitors in Fetal Lung Cells Exposed to Mechanical Stretch: Regulation by IL-10. Lung 189 (4), 341-349. doi:10.1007/s00408-011-9310-7

Hawwa, R. L., Hokenson, M. A., Wang, Y., Huang, Z., Sharma, S., and SanchezEsteban, J. (2011a). IL-10 Inhibits Inflammatory Cytokines Released by Fetal Mouse Lung Fibroblasts Exposed to Mechanical Stretch. Pediatr. Pulmonol. 46 (7), 640-649. doi:10.1002/ppul.21433

Hendricks, P., Diaz, F. J., Schmitt, S., Sitta Sittampalam, G., and Nirmalanandhan, V. S. (2012). Effects of Respiratory Mechanical Forces on the Pharmacological Response of Lung Cancer Cells to Chemotherapeutic Agents. Fund. Clin. Pharmacol. 26 (5), 632-643. doi:10.1111/j.1472-8206.2011.00964.x

Hinz, B. (2012). Mechanical Aspects of Lung Fibrosis. Proc. Am. Thorac. Soc. 9 (3), 137-147. doi:10.1513/pats.201202-017AW

Hsia, C. C. W., Hyde, D. M., and Weibel, E. R. (2016). Lung Structure and the Intrinsic Challenges of Gas Exchange. Compr. Physiol. 6 (2), 827-895. doi:10.1002/cphy.c150028

Huang, Y., Haas, C., and Ghadiali, S. N. (2010). Influence of Transmural Pressure and Cytoskeletal Structure on NF-Kb Activation in Respiratory Epithelial Cells. Cel. Mol. Bioeng. 3 (4), 415-427. doi:10.1007/s12195-010-0138-7

Huh, D., Matthews, B. D., Mammoto, A., Montoya-Zavala, M., Hsin, H. Y., and Ingber, D. E. (2010). Reconstituting Organ-Level Lung Functions on a Chip. Science 328 (5986), 1662-1668. doi:10.1126/science.1188302

Indra, I., Undyala, V., Kandow, C., Thirumurthi, U., Dembo, M., and Beningo, K. A. (2011). Anin Vitrocorrelation of Mechanical Forces and Metastatic Capacity. Phys. Biol. 8 (1), 015015. doi:10.1088/1478-3975/8/1/015015

Jang, I., and Beningo, K. (2019). Integrins, CAFs and Mechanical Forces in the Progression of Cancer. Cancers 11 (5), 721. doi:10.3390/cancers11050721

Jones, J. (2011). Substrate Stiffness Regulates Extracellular Matrix Deposition by Alveolar Epithelial Cells. Rrb 2, 1-12. doi:10.2147/RRB.S13178

Kalluri, R. (2016). The Biology and Function of Fibroblasts in Cancer. Nat. Rev. Cancer 16 (9), 582-598. doi:10.1038/nrc.2016.73

Kalluri, R., and Zeisberg, M. (2006). Fibroblasts in Cancer. Nat. Rev. Cancer 6 (5), 392-401. doi:10.1038/nrc1877

Kotaru, C., Schoonover, K. J., Trudeau, J. B., Huynh, M.-L., Zhou, X., Hu, H., et al. (2006). Regional Fibroblast Heterogeneity in the Lung. Am. J. Respir. Crit. Care Med. 173 (11), 1208-1215. doi:10.1164/rccm.200508-1218OC

Kouranos, V., Ward, S., Kokosi, M. A., Castillo, D., Chua, F., Judge, E. P., et al. (2020). Mixed Ventilatory Defects in Pulmonary Sarcoidosis. Chest 158 (5), 2007-2014. doi:10.1016/j.chest.2020.04.074

Kumar, S., and Weaver, V. M. (2009). Mechanics, Malignancy, and Metastasis: The Force Journey of a Tumor Cell. Cancer Metastasis Rev. 28 (1-2), 113-127. doi:10.1007/s10555-008-9173-4

Ladoux, B., Mège, R.-M., and Trepat, X. (2016). Front-Rear Polarization by Mechanical Cues: From Single Cells to Tissues. Trends Cel Biol. 26 (6), 420-433. doi:10.1016/j.tcb.2016.02.002

Lemos, D. R., and Duffield, J. S. (2018). Tissue-resident Mesenchymal Stromal Cells: Implications for Tissue-specific Antifibrotic Therapies. Sci. Transl. Med. 10 (426). doi:10.1126/scitranslmed.aan5174

Liu, F., Mih, J. D., Shea, B. S., Kho, A. T., Sharif, A. S., Tager, A. M., et al. (2010). Feedback Amplification of Fibrosis through Matrix Stiffening and COX-2 Suppression. J. Cel Biol. 190 (4), 693-706. doi:10.1083/jcb.201004082

Lugano, R., Ramachandran, M., and Dimberg, A. (2020). Tumor Angiogenesis: Causes, Consequences, Challenges and Opportunities. Cell. Mol. Life Sci. 77 (9), 1745-1770. doi:10.1007/s00018-019-03351-7

Mahto, S. K., Tenenbaum-Katan, J., Greenblum, A., Rothen-Rutishauser, B., and Sznitman, J. (2014). Microfluidic Shear Stress-Regulated Surfactant Secretion in Alveolar Epithelial Type II Cells In Vitro. Am. J. Physiology-Lung Cell Mol. Physiol. 306 (7), L672-L683. doi:10.1152/ajplung.00106.2013

Markowski, M. C., Brown, A. C., and Barker, T. H. (2012). Directing Epithelial to Mesenchymal Transition through Engineered Microenvironments Displaying 
Orthogonal Adhesive and Mechanical Cues. J. Biomed. Mater. Res. 100A (8), 2119-2127. doi:10.1002/jbm.a.34068

Menon, S., Beningo, K. A., and Gullberg, D. (2011). Cancer Cell Invasion Is Enhanced by Applied Mechanical Stimulation. PLoS One 6 (2), e17277. doi:10.1371/journal.pone.0017277

Murata, N., Ito, S., Furuya, K., Takahara, N., Naruse, K., Aso, H., et al. (2014). Ca2+ Influx and ATP Release Mediated by Mechanical Stretch in Human Lung Fibroblasts. Biochem. Biophysical Res. Commun. 453 (1), 101-105. doi:10.1016/ j.bbrc.2014.09.063

Najrana, T., Mahadeo, A., Abu-Eid, R., Kreienberg, E., Schulte, V., Uzun, A., et al. (2020). Mechanical Stretch Regulates the Expression of Specific miRNA in Extracellular Vesicles Released from Lung Epithelial Cells. J. Cel. Physiol. 235 (11), 8210-8223. doi:10.1002/jcp.29476

Nalayanda, D. D., Puleo, C. M., Fulton, W. B., Wang, T.-H., and Abdullah, F. (2009). Characterization of Pulmonary Cell Growth Parameters in a Continuous Perfusion Microfluidic Environment. Exp. Lung Res. 33 (6), 321-335. doi:10.1080/01902140701557754

Ng, C. P., and Swartz, M. A. (2003). Fibroblast Alignment under Interstitial Fluid Flow Using a Novel 3-D Tissue Culture Model. Am. J. Physiology-Heart Circulatory Physiol. 284 (5), H1771-H1777. doi:10.1152/ajpheart.01008.2002

Novak, C., Ballinger, M. N., and Ghadiali, S. (2021). Mechanobiology of Pulmonary Diseases: A Review of Engineering Tools to Understand Lung Mechanotransduction. J. Biomechanical Eng. 143 (11), 110801. doi:10.1115/ 1.4051118

Nurmik, M., Ullmann, P., Rodriguez, F., Haan, S., and Letellier, E. (2019). In Search of Definitions: Cancer-associated Fibroblasts and Their Markers. Int. J. Cancer 146 (4), 895-905. doi:10.1002/ijc.32193

Öhlund, D., Elyada, E., and Tuveson, D. (2014). Fibroblast Heterogeneity in the Cancer Wound. J. Exp. Med. 211 (8), 1503-1523. doi:10.1084/ jem.20140692

Pazolli, E., Luo, X., Brehm, S., Carbery, K., Chung, J.-J., Prior, J. L., et al. (2009). Senescent Stromal-Derived Osteopontin Promotes Preneoplastic Cell Growth. Cancer Res. 69 (3), 1230-1239. doi:10.1158/0008-5472.CAN-08-2970

Pechkovsky, D. V., Hackett, T. L., An, S. S., Shaheen, F., Murray, L. A., and Knight, D. A. (2010). Human Lung Parenchyma but Not Proximal Bronchi Produces Fibroblasts with Enhanced TGF- $\beta$ Signaling and $\alpha$-SMA Expression. Am. J. Respir. Cel Mol Biol 43 (6), 641-651. doi:10.1165/rcmb.2009-0318OC

Pereira, B. A., Vennin, C., Papanicolaou, M., Chambers, C. R., Herrmann, D., Morton, J. P., et al. (2019). CAF Subpopulations: A New Reservoir of Stromal Targets in Pancreatic Cancer. Trends Cancer 5 (11), 724-741. doi:10.1016/ j.trecan.2019.09.010

Pittenger, M. F., Discher, D. E., Péault, B. M., Phinney, D. G., Hare, J. M., and Caplan, A. I. (2019). Mesenchymal Stem Cell Perspective: Cell Biology to Clinical Progress. NPJ Regen. Med. 4, 22. doi:10.1038/s41536-019-0083-6

Plikus, M. V., Guerrero-Juarez, C. F., Ito, M., Li, Y. R., Dedhia, P. H., Zheng, Y., et al. (2017). Regeneration of Fat Cells from Myofibroblasts during Wound Healing. Science 355 (6326), 748-752. doi:10.1126/science.aai8792

Plikus, M. V., Wang, X., Sinha, S., Forte, E., Thompson, S. M., Herzog, E. L., et al. (2021). Fibroblasts: Origins, Definitions, and Functions in Health and Disease. Cell 184 (15), 3852-3872. doi:10.1016/j.cell.2021.06.024

Raghu, G., Collard, H. R., Egan, J. J., Martinez, F. J., Behr, J., Brown, K. K., et al. (2011). An Official ATS/ERS/JRS/ALAT Statement: Idiopathic Pulmonary Fibrosis: Evidence-Based Guidelines for Diagnosis and Management. Am. J. Respir. Crit. Care Med. 183 (6), 788-824. doi:10.1164/rccm.2009-040GL

Raghu, G., Rochwerg, B., Zhang, Y., Garcia, C. A. C., Azuma, A., Behr, J., et al. (2015). An Official ATS/ERS/JRS/ALAT Clinical Practice Guideline: Treatment of Idiopathic Pulmonary Fibrosis. An Update of the 2011 Clinical Practice Guideline. Am. J. Respir. Crit. Care Med. 192 (2), e3-e19. doi:10.1164/ rccm.201506-1063ST

Rápalo, G., Herwig, J. D., Hewitt, R., Wilhelm, K. R., Waters, C. M., and Roan, E. (2015). Live Cell Imaging during Mechanical Stretch. JoVE 102, e52737. doi: $10.3791 / 52737$

Riteau, N., Gasse, P., Fauconnier, L., Gombault, A., Couegnat, M., Fick, L., et al. (2010). Extracellular ATP Is a Danger Signal Activating P2X7Receptor in Lung Inflammation and Fibrosis. Am. J. Respir. Crit. Care Med. 182 (6), 774-783. doi:10.1164/rccm.201003-0359OC

Roshanzadeh, A., Nguyen, T. T., Nguyen, K. D., Kim, D.-S., Lee, B.-K., Lee, D.-W., et al. (2020). Mechanoadaptive Organization of Stress Fiber Subtypes in
Epithelial Cells under Cyclic Stretches and Stretch Release. Sci. Rep. 10 (1). doi:10.1038/s41598-020-75791-2

Sakamoto, Y., Ishijima, M., Kaneko, H., Kurebayashi, N., Ichikawa, N., Futami, I., et al. (2010). Distinct Mechanosensitive Ca2+influx Mechanisms in Human Primary Synovial Fibroblasts. J. Orthop. Res. 28 (7), a-n. doi:10.1002/jor.21080 Sanchez-Esteban, J., Wang, Y., Cicchiello, L. A., and Rubin, L. P. (2002). Cyclic Mechanical Stretch Inhibits Cell Proliferation and Induces Apoptosis in Fetal Rat Lung Fibroblasts. Am. J. Physiology-Lung Cell Mol. Physiol. 282 (3), L448-L456. doi:10.1152/ajplung.00399.2000

Shikata, Y., Rios, A., Kawkitinarong, K., Depaola, N., Garcia, J., and Birukov, K. (2005). Differential Effects of Shear Stress and Cyclic Stretch on Focal Adhesion Remodeling, Site-specific FAK Phosphorylation, and Small GTPases in Human Lung Endothelial Cells. Exp. Cel Res. 304 (1), 40-49. doi:10.1016/ j.yexcr.2004.11.001

Shukla, V. C., Higuita-Castro, N., Nana-Sinkam, P., and Ghadiali, S. N. (2016). Substrate Stiffness Modulates Lung Cancer Cell Migration but Not Epithelial to Mesenchymal Transition. J. Biomed. Mater. Res. 104 (5), 1182-1193. doi:10.1002/jbm.a.35655

Song, J., Hu, B., Qu, H., Wang, L., Huang, X., Li, M., et al. (2020). Upregulation of Angiotensin Converting Enzyme 2 by Shear Stress Reduced Inflammation and Proliferation in Vascular Endothelial Cells. Biochem. Biophysical Res. Commun. 525 (3), 812-818. doi:10.1016/j.bbrc.2020.02.151

Su, S., Chen, J., Yao, H., Liu, J., Yu, S., Lao, L., et al. (2018). CD10+GPR77+ CancerAssociated Fibroblasts Promote Cancer Formation and Chemoresistance by Sustaining Cancer Stemness. Cell 172 (4), 841-856. doi:10.1016/ j.cell.2018.01.009

Szulcek, R., Happé, C. M., Rol, N., Fontijn, R. D., Dickhoff, C., Hartemink, K. J., et al. (2016). Delayed Microvascular Shear Adaptation in Pulmonary Arterial Hypertension. Role of Platelet Endothelial Cell Adhesion Molecule-1 Cleavage. Am. J. Respir. Crit. Care Med. 193 (12), 1410-1420. doi:10.1164/rccm.201506$12310 \mathrm{OC}$

Tomasek, J. J., Gabbiani, G., Hinz, B., Chaponnier, C., and Brown, R. A. (2002). Myofibroblasts and Mechano-Regulation of Connective Tissue Remodelling. Nat. Rev. Mol. Cel Biol 3 (5), 349-363. doi:10.1038/nrm809

Torrino, S., Grasset, E. M., Audebert, S., Belhadj, I., Lacoux, C., Haynes, M., et al. (2021). Mechano-induced Cell Metabolism Promotes Microtubule Glutamylation to Force Metastasis. Cel Metab. 33 (7), 1342-1357. doi:10.1016/j.cmet.2021.05.009

Tousoulis, D., Kampoli, A.-M., Tentolouris Nikolaos Papageorgiou, C., and Stefanadis, C. (2012). The Role of Nitric Oxide on Endothelial Function. Cvp 10 (1), 4-18. doi:10.2174/157016112798829760

Tschumperlin, D. J., and Margulies, S. S. (1999). Alveolar Epithelial Surface AreaVolume Relationship in Isolated Rat Lungs. J. Appl. Physiol. 86 (6), 2026-2033. doi:10.1152/jappl.1999.86.6.2026

Tschumperlin, D. J., and Margulies, S. S. (1998). Equibiaxial Deformation-Induced Injury of Alveolar Epithelial Cells In Vitro. Am. J. Physiology-Lung Cell Mol. Physiol. 275 (6), L1173-L1183. doi:10.1152/ajplung.1998.275.6.L1173

Tschumperlin, D. J., Oswari, J., and Margulies, A. S. S. (2000). DeformationInduced Injury of Alveolar Epithelial Cells. Am. J. Respir. Crit. Care Med. 162 (2), 357-362. doi:10.1164/ajrccm.162.2.9807003

Tsukui, T., Ueha, S., Abe, J., Hashimoto, S.-i., Shichino, S., Shimaoka, T., et al. (2013). Qualitative rather Than Quantitative Changes Are Hallmarks of Fibroblasts in Bleomycin-Induced Pulmonary Fibrosis. Am. J. Pathol. 183 (3), 758-773. doi:10.1016/j.ajpath.2013.06.005

Wang, W.-H., Hsu, C.-L., Huang, H.-C., and Juan, H.-F. (2020). Quantitative Phosphoproteomics Reveals Cell Alignment and Mitochondrial Length Change under Cyclic Stretching in Lung Cells. Ijms 21 (11), 4074. doi:10.3390/ ijms 21114074

Wei, J.-R., Dong, J., and Li, L. (2020). Cancer-associated Fibroblasts-Derived Gamma-Glutamyltransferase 5 Promotes Tumor Growth and Drug Resistance in Lung Adenocarcinoma. Aging 12 (13), 13220-13233. doi:10.18632/aging.103429

Xie, T., Wang, Y., Deng, N., Huang, G., Taghavifar, F., Geng, Y., et al. (2018). Single-Cell Deconvolution of Fibroblast Heterogeneity in Mouse Pulmonary Fibrosis. Cel Rep. 22 (13), 3625-3640. doi:10.1016/j.celrep.2018.03.010

Xie, Y., Qian, Y., Wang, Y., Liu, K., and Li, X. (2020). Mechanical Stretch and LPS Affect the Proliferation, Extracellular Matrix Remodeling and Viscoelasticity of Lung Fibroblasts. Exp. Ther. Med. 20 (5), 1. doi:10.3892/etm.2020.9133 
Xu, F., Cui, W., Zhao, Z., Gong, W., Wei, Y., Liu, J., et al. (2017). Targeting Tumor Microenvironment: Effects of Chinese Herbal Formulae on MacrophageMediated Lung Cancer in Mice. Evidence-Based Complement. Altern. Med. 2017, 1-12. doi:10.1155/2017/7187168

Yamamoto, K., Imamura, H., and Ando, J. (2018). Shear Stress Augments Mitochondrial ATP Generation that Triggers ATP Release and $\mathrm{Ca} 2+$ Signaling in Vascular Endothelial Cells. Am. J. Physiology-Heart Circulatory Physiol. 315 (5), H1477-H1485. doi:10.1152/ajpheart.00204.2018

Yamauchi, M., Gibbons, D. L., Zong, C., Fradette, J. J., Bota-Rabassedas, N., and Kurie, J. M. (2020). Fibroblast Heterogeneity and its Impact on Extracellular Matrix and Immune Landscape Remodeling in Cancer. Matrix Biol. 91-92, 8-18. doi:10.1016/j.matbio.2020.05.001

Zhang, Y., Wang, S., Lai, Q., Fang, Y., Wu, C., Liu, Y., et al. (2020). Cancerassociated Fibroblasts-Derived Exosomal miR-17-5p Promotes Colorectal Cancer Aggressive Phenotype by Initiating a RUNX3/MYC/TGF- $\beta 1$ Positive Feedback Loop. Cancer Lett. 491, 22-35. doi:10.1016/ j.canlet.2020.07.023
Conflict of Interest: The authors declare that the research was conducted in the absence of any commercial or financial relationships that could be construed as a potential conflict of interest.

Publisher's Note: All claims expressed in this article are solely those of the authors and do not necessarily represent those of their affiliated organizations, or those of the publisher, the editors, and the reviewers. Any product that may be evaluated in this article, or claim that may be made by its manufacturer, is not guaranteed or endorsed by the publisher.

Copyright $\odot 2021$ Gong, Yang, Wen, Wang, Li and Dai. This is an open-access article distributed under the terms of the Creative Commons Attribution License (CC $B Y)$. The use, distribution or reproduction in other forums is permitted, provided the original author(s) and the copyright owner(s) are credited and that the original publication in this journal is cited, in accordance with accepted academic practice. No use, distribution or reproduction is permitted which does not comply with these terms. 